\title{
Twin pregnancies in the Niger Delta of Nigeria: a four-year review
}

This article was published in the following Dove Press journal:

International Journal of Women's Health

24 May 2012

Number of times this article has been viewed

Isa Ibrahim'

Abisoye Oyeyemi²

Abhulimen Obilahi ${ }^{2}$

'Department of Obstetrics, ${ }^{2}$ Epidemiology Division, Department of Public Health, Ministry of Health, Bayelsa State, Nigeria
Correspondence: Isa Ibrahim

Department of Obs and Gynae, College of Health Sciences, Niger Delta University, Amassoma, Bayelsa State, Nigeria

Tel +23470 3l8I 9695

Email daddayzee@yahoo.com
Background: The female is programmed to nurture one fetus and to take care of one neonate at a time; hence, twin pregnancy is associated with an increased risk of preterm deliveries, perinatal morbidity, and mortality and maternal complications. This study aimed to determine the twinning rate, and maternal and fetal outcomes of all twin pregnancies managed at the Niger Delta University Teaching Hospital Okolobiri.

Methods: The study is a 4-year descriptive retrospective evaluation of twin pregnancies managed at the Niger Delta University Teaching Hospital Okolobiri. Records of all pregnancies, booked and unbooked, managed from January 1, 2007 to December 31, 2010 were reviewed. Details of delivery and maternal and fetal outcomes were obtained using a pro forma designed for the study. Epi Info version 3.5.3 was used for statistical analysis. The Chi-square test was used to test for associations between variables. The level of significance was set at $P \leq 0.05$.

Results: A total of 1341 deliveries including 41 cases of twin deliveries were recorded during the study period, giving an incidence of 30.6/1000. Twenty-nine (70.7\%) of the patients were unbooked. The mean gestational age was $33.3 \pm 2.6$ weeks, and the mean fetal weight was $2.34 \pm 0.54 \mathrm{~kg}$. There were 13 perinatal deaths, with a perinatal mortality rate of $158.5 / 1000$. There was no association between booking status and perinatal mortality rate $\left(\chi^{2}=0.017\right.$, $P=1.000)$. Prematurity was the chief cause of perinatal death $(65.4 \%)$. Maternal morbidities included anemia, wound infection, and genital sepsis. There were no maternal deaths.

Conclusion: The twinning rate was high. There was a high perinatal mortality rate, with prematurity accounting for most of the mortality. There is a need for improved incubation/neonatal care for better outcomes with twin pregnancies in the hospital.

Keywords: twin pregnancy, Niger Delta, maternal outcome, perinatal outcome

\section{Introduction}

Twin pregnancy refers to the presence of two fetuses in the uterus. ${ }^{1}$ It results commonly from the fertilization of two separate ova (dizygotic) and about one third of cases arises from division of one fertilized ovum into two separate embryo (monozygotic). ${ }^{1}$ There are considerable ethnic, racial, and geographical variations in the frequency of twin pregnancy.

The reported spontaneous twinning rate in the Yoruba-speaking western part of Nigeria is the highest in the world, with values as high as 45 per 1000 deliveries ( 1 in 22 deliveries) being reported. ${ }^{2-4} \mathrm{~A}$ rate of 1 in 36.2 has been reported among the Igbos in Nigeria. ${ }^{5}$

The incidence of spontaneous twinning is higher in black women than in Caucasians and Asians. ${ }^{2}$ It is about 1 in 83 deliveries in Caucasian women, being lowest in Asians. 
The difference in twinning rates seems to be due to differences in the incidence of dizygotic births, while the monozygotic rate varies very little between races and occurs with a constant incidence of 3.9 per 1000 births $^{6}{ }^{6}$ The incidence of twinning in developed countries has been rising over the last 20 years. The increase is entirely due to assisted reproductive technologies and ovulation induction agents. ${ }^{7}$ Twins now comprise $25 \%-30 \%$ of all deliveries resulting from assisted reproductive techniques. ${ }^{8}$ Other factors associated with twinning include heredity (family history of twinning, especially in a first-degree relative on the maternal side), increasing maternal age and parity, maternal height, weight for height, previous twin deliveries, use of ovulation induction agents, easy conception (usually within 3 months of marriage), and pregnancy soon after cessation of long-term oral contraceptive use. ${ }^{8}$

Well known complications of twin pregnancy include abortion, hyperemesis gravidarum, congenital malformations, anemia, pregnancy-induced hypertension, intrauterine growth restriction, preterm labor, prelabor spontaneous rupture of membranes, and antepartum hemorrhage. Others are malpresentation, abnormal lie, polyhydramnios, cord prolapse, cord entanglement, urinary tract infection, postpartum hemorrhage, retained second twin, and increased operative vaginal delivery. ${ }^{7-11}$

Prematurity poses the greatest threat to twins, with an associated perinatal mortality rate of 3-8 times that of a singleton pregnancy. ${ }^{1}$ Elective hospitalization for bed rest, prophylactic use of tocolytics, and use of cervical cerclage are measures proposed to reduce the high fetal wastage associated with premature labor in multiple pregnancies, but these have not been shown conclusively to be beneficial. ${ }^{7,8}$ However, during the past decade, maternal nutritional intervention has emerged as the only means that consistently improves outcome in twin pregnancy. ${ }^{12}$ From the available guidelines, it appears that most clinicians would consider nonvertex first sets as an indication for cesarean section ${ }^{13}$ and vertex first twins as candidates for vaginal delivery. Controversy exists for vertex-nonvertex pairs. ${ }^{14}$

This study aimed to determine the twinning rate and describe maternal and fetal outcomes of all twin pregnancies managed at the Niger Delta University Teaching Hospital Okolobiri over a 4-year period.

\section{Materials and methods}

This study is a 4-year retrospective review of all twin pregnancies managed from January 1, 2007 to December 31, 2010 at the Niger Delta University Teaching Hospital
Okolobiri, a tertiary hospital in Bayelsa State. The sources of information were patient case notes, and antenatal, labor, neonatal ward, and theater records. The total number of deliveries, fetal outcome, and numbers of labor and postnatal ward admissions were obtained for the period under review. The information obtained was coded and transferred onto a pro forma designed for the study. Data collected were analyzed using Epi Info version 3.5.3. Frequencies were generated for variables including maternal age, parity, booking status, birth weight, baby's gender, and maternal and perinatal outcomes. The Chi-square test was used to test for any association between variables of interest. The level of significance was set at $P \leq 0.05$. The following operational definitions were used during the conduct of this study: prematurity, ie, a baby born before 37 weeks of gestation, counting from the first day of the last menstrual period, and perinatal death, ie, all still births, plus death in first week after birth.

\section{Results}

During the 4-year period of the study, there were 41 twin deliveries out of a total of 1341 deliveries, giving an overall incidence of twin delivery of 30.6/1000 or 1 in 33 deliveries. Table 1 shows the sociodemographic characteristics of the patients. Their age ranged from 17 to 41 years, with a mean of $28.1 \pm 5.7$ years. The majority ( 19 , $46.3 \%$ ) of the patients were aged 30-39 years, and four

Table I Sociodemographic characteristics of patients

\begin{tabular}{lll}
\hline Characteristic & Frequency $(\mathbf{n}=\mathbf{4 1})$ & Percentage (\%) \\
\hline Age (years) & & \\
$\leq 19$ & 4 & 9.8 \\
$20-29$ & 16 & 39.0 \\
$30-39$ & 19 & 46.3 \\
$\geq 40$ & 2 & 4.9 \\
Parity & & \\
0 & 5 & 12.2 \\
I-3 & 22 & 53.7 \\
$\geq 4$ & 14 & 34.1 \\
Educational status & & \\
Nil & 6 & 14.6 \\
Primary education & 11 & 26.8 \\
Secondary education & 18 & 43.9 \\
Tertiary & 6 & 14.6 \\
Booking status & & \\
Booked & 12 & 29.3 \\
Unbooked & 29 & 70.7 \\
Gestation age at delivery (weeks) & \\
$30-31$ & 4 & 9.8 \\
$32-34$ & 9 & 21.9 \\
$35-36$ & 16 & 39.0 \\
$37-39$ & 12 & 29.3 \\
\hline
\end{tabular}


$(9.8 \%)$ of the patients were teenagers. Their parity was $0-6$, with a mean of $2.4 \pm 1.9$. About a third $(14,34.1 \%)$ were grand multiparous, $24(58.5 \%)$ had at least secondary education, and the majority $(29,70.7 \%)$ were unbooked. The mean gestational age was $33.3 \pm 2.6$ weeks, and mean fetal weight was $2.34 \pm 0.54 \mathrm{~kg}$. There was no statistically significant difference in mean weight between first and second twins $(P=0.550)$. There were more males (42, $51.2 \%)$ than females, and more low birth weight babies (44, 53.7\%). The most common mode of presentation was cephalic/cephalic $(25,61.0 \%)$, followed by cephalic/breech (seven, 17.1\%), breech/cephalic (five, 12.2\%), and breech/ breech (four, 9.7\%).

Twenty sets (48.8\%) of twins were delivered by cesarean section, the majority $(16,80 \%)$ of which were emergencies. Eighteen sets (43.9\%) had spontaneous vaginal delivery, while three $(7.3 \%)$ had a combination of assisted vaginal breech delivery and instrumental vaginal delivery. Figure 1 shows the indications for emergency cesarean section. The two commonest indications were breech presentation (second twin cephalic) $3 / 18.8 \%$, and severe pre-eclampsia/ eclampsia $3 / 18.8 \%$. The indications for all cesarean sections performed are shown in Table 2. The three commonest indications were breech presentation (second twin cephalic) $6 / 30 \%$, breech presentation (second twin breech) $3 / 15 \%$, and eclampsia/severe pre-eclampsia $3 / 15 \%$. Table 3 shows the maternal morbidities in the patients who had cesarean section.

The causes of perinatal mortality are presented in Table 4 . There were 13 perinatal deaths, comprising nine in the unbooked patients, with a perinatal mortality rate of $155.2 / 1000$, compared with four in the booked patients, with a perinatal mortality rate of $166.7 / 1000\left(\chi^{2}=0.017\right.$, $P=1.0$ ). The overall perinatal mortality rate was $158.5 / 1000$. Prematurity accounted for $61.5 \%$ of these deaths.

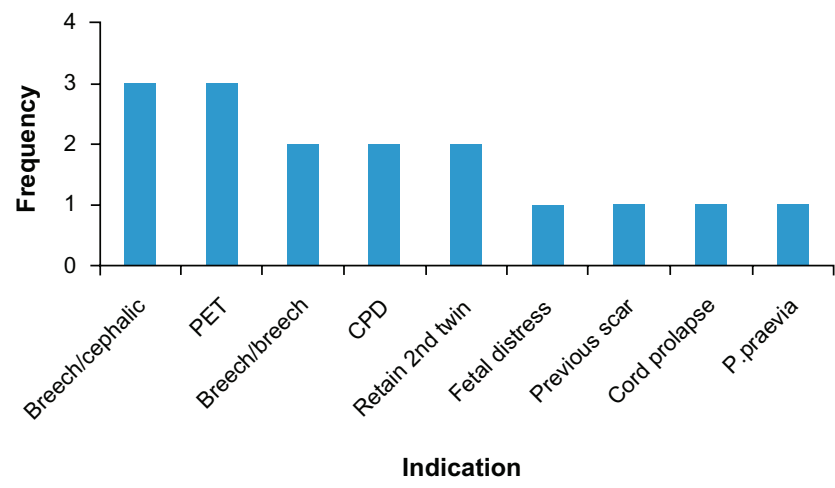

Figure I Indication for emergency cesarean section. Abbreviation: PET, pre-eclamptic toxemia; CPD, cephalopelvic disproportion.
Table 2 Indication for cesarean section

\begin{tabular}{lll}
\hline Indication & Frequency & Percentage \\
\hline Breech/cephalic & 6 & 30 \\
Breech/breech & 3 & 15 \\
Eclampsia and severe pre-eclampsia & 3 & 15 \\
Cephalopelvic disproportion & 2 & 10 \\
Retained second twin & 2 & 10 \\
Fetal distress in labour & 1 & 5 \\
Antepartum hemorrhage, placenta previa & 1 & 5 \\
One previous cesarean section & 1 & 5 \\
Cord prolapse & 1 & 5 \\
Total & $\mathbf{2 0}$ & $\mathbf{1 0 0 . 0}$ \\
\hline
\end{tabular}

\section{Discussion}

The twining rate of 30.6 per 1000 (one in 33) in this study was lower than the 53 per 1000 deliveries (one in 19) reported among the Yorubas in the Western part of Nigeria and one in 24 reported among the Igbos,${ }^{14}$ but higher than the one in 76 reported from a similar institution in Maiduguri, Nigeria. ${ }^{15}$ The species of yam (Dioscorea rotundata) found in the Yoruba land is said to contain an ovulation induction agent and this may explain the high incidence of multiple pregnancy among the Yorubas in Nigeria. ${ }^{16}$ However, a decline in this rate has been observed. ${ }^{17}$ Thus, the twinning rate in Nigeria is probably influenced by factors other than ethnicity.

In this study, $46.3 \%$ of the patients were aged $30-39$ years, which is lower than the $77 \%$ reported from a study in another developing country. ${ }^{18}$ Over $30 \%$ of the patients in this study were grand multiparous. Older age and high parity are two strong independent factors associated with an increased incidence of twinning. ${ }^{11}$

Regarding the mode of delivery, the guidelines are mainly based on presentation, fetal weight, and well being. These guidelines have not changed over past decades, and national data from the US and the UK suggest that about $60 \%$ of multiples are delivered by cesarean section. ${ }^{13}$ Cesarean section has been advised where the first twin is breech,

Table 3 Morbidity among patients who had emergency cesarean section

\begin{tabular}{lll}
\hline Complication & Frequency $(\mathbf{n}=\mathbf{2 0})$ & Percentage* \\
\hline Anemia & 9 & 45 \\
Wound infection & 7 & 35 \\
Genital sepsis & 5 & 25 \\
Thrombophlebitis & 3 & 15 \\
Septicemia & 2 & 10 \\
Post-partum hemorrhage & 2 & 10 \\
Acute renal failure & 1 & 5 \\
Tetanus & 1 & 5 \\
\hline
\end{tabular}

Note: *Some women had more than one complication. 
Table 4 Causes of perinatal death

\begin{tabular}{lll}
\hline Cause & Frequency & Percentage \\
\hline Prematurity & 8 & 61.5 \\
Anteparturm hemorrhage & 2 & 15.4 \\
Eclampsia and severe pre-eclampsia & 2 & 15.4 \\
Retained second twin & $\mathrm{I}$ & 7.7 \\
Total & I3 & $\mathbf{1 0 0}$ \\
\hline
\end{tabular}

based on extrapolation from the Term Breech Trial, and the desire to avoid the rare interlocking with head entrapment of a presenting breech above a second cephalic twin. The presentation of the second twin is of little relevance until after the birth of the first.

In this study, $48.8 \%$ of women underwent cesarean section ( $80.0 \%$ of which were emergency cesarean sections). This is higher than the $10.6 \%{ }^{15}$ but lower than the $60 \%{ }^{19}$ reported from previous studies. The reason is that most of these patients were referred from private and public primary and secondary health facilities within and sometimes outside Bayelsa. Often, the women had been in labor for more than 24 hours at these centers and were often referred late in the night for various reasons, hence the high rate of emergency procedures. The high cesarean section rate is a major public health problem because cesarean section increases the health risk for both mothers and their babies, as well as the cost of health care compared with normal deliveries. ${ }^{20}$ Furthermore, doubt has been raised about whether the observed increase in cesarean section can be justified in terms of perinatal statistics. In developed countries, there has been no significant diminution in the perinatal mortality rate despite the increase in the cesarean section rates. ${ }^{21}$

Essentially the risks of vaginal delivery are increased in twins compared with singletons, as are the risks of cesarean section. ${ }^{22}$ Therefore, it is not surprising that maternal morbidity was high in this study. Evidence from other studies suggest that maternal morbidity from cesarean section is comparable with that of vaginal delivery where the emergency rate exceeds one in three, ${ }^{23}$ as was found in this study where most of the cesarean sections were performed as emergencies, with some patients admitted with dehydration, intrapartum genital sepsis, or anemia, all of which further enhance the risk of post partum infection. Anemia was the commonest complication in this group of women with cesarean section (nine, $45.0 \%$ ). Others were wound infection (seven, $35.0 \%$ ), genital sepsis (five, $25.0 \%$ ), and thrombophlebitis (three, $15.0 \%$ ).

There were 13 perinatal deaths, which gives a perinatal mortality rate of 158.5 per 1000 . Over $70 \%$ of the babies were delivered prematurely and more than half were of low birth weight. Prematurity and low birth weight are two major causes of perinatal death, especially in the developing world where facilities and supportive care are inadequate, the Niger Delta University Teaching Hospital being no exception. Other identified causes that may explain the poor birth outcome include failure to diagnose twinning before the onset of labor, birth asphyxia, a retained second twin, and malpresentation. The referral system in this state is inadequate because most primary and secondary health facilities are remotely located with poor access to places like the Niger Delta University Teaching Hospital, where further help could be sought. Most state hospitals are also limited in facilities and expertise. Private hospitals also contribute to the poor outcomes experienced in the hospital. A great number of them persevere with labor cases beyond what they can handle for career and economic reasons, and refer only when complications have set in. Although the perinatal mortality rate of $158.5 / 1000$ births in this study is similar to that reported by other studies, ${ }^{15,19}$ it is higher than the perinatal mortality rate of $79.6 / 1000$ for singleton births during the study period. Not all the women delivered at the hospital were from Bayelsa State, and some were referred from neighboring states. Therefore, the twinning rate in this study may be an overestimate of the true rate in the area that the hospital primarily serves.

In conclusion, twinning has always been an important topic not only medically but also socially and economically in obstetric practice in Nigeria because of the high twinning rate in the country. The perinatal mortality was higher than for singletons in this study, and prematurity was largely responsible. We recommend that the hospital should apply interventions that will minimize premature delivery in twin pregnancies and improve on its incubation/ neonatal care.

\section{Acknowledgment}

We acknowledge all the hospital staff members who assisted in collection of the study data.

\section{Disclosure}

The authors report no conflicts of interest in this work.

\section{References}

1. Nkyekyer K. Multiple pregnancy. In: Kwawukwume EY, Emuveyan EE, editors. Comprehensive Obstetrics in the Tropics. Accra, Ghana: Asante and Hittscher Printing Press Ltd; 2002.

2. Abudu OO, Anorlu RI. Multiple pregnancy. In: Agboola A, editor. Textbook of Obstetrics and Gynaecology for Medical Students, 2nd ed. Ibadan, Nigeria: Heinemann Educational Books; 2006.

3. Fisk NM. Multiple pregnancy. In: Edmonds K, editor. Dewhurst's Textbook of Obstetrics and Gynaecology for Postgraduates, 7th ed. Oxford, UK: Blackwell Scientific Publication; 2007. 
4. Akinkugbe A. Multiple pregnancy. In: A Textbook of Obstetrics and Gynaecology. Ibadan, Nigeria: Evans Brothers Nigeria Publishers Ltd; 1996.

5. Adinma JIB, Agbai AO. Pattern of twin birth in Nigerian Igbo women. West Afr J Med. 1994;13:234-236.

6. Olayemi OO, Adeniji AR, Aimakhu CO. Determinant of perinatal mortality in twins at Ibadan. Trop J Obstet Gynaecol. 2002;19: 36-38.

7. Martin JA, Hamilton BE, Sutton PD, Ventura SJ, Menacker F, Munson ML. Births: final data for 2002. Natl Vital Stat Report. 2003;52:1-113.

8. Fakeye O. Perinatal factors in twin mortality in Nigeria. Int J Gynaecol Obstet. 1986;24:309-314.

9. Obisesan KA, Arowojolu AO, Ilesanmi AO, Roberts OA, Fawole O. Relative risk associated with the second-born twin at birth. Nig J Clin Pract. 1999;2:13-14.

10. Pernoll ML, Melissa M. Multiple pregnancy. In: Decherney DH, Pernoll ML, editors. Current Obstetric and Gynaecologic Diagnosis and Treatment, 9th ed. New York, NY: McGraw-Hill and Lange Medical Books; 2003.

11. Luke B. Improving multiple pregnancy outcomes with nutritional interventions. Clin Obstet Gynecol. 2004;47:146-162.

12. Blickstein I, Goldman RD, Kupferminc M. Delivery of breech first twins: a multicenter retrospective study. Obstet Gynecol. 2000;95:37-42.

13. Hogle KI, Hutton EK, Mcbrien KA, Barret JF, Hannah ME. Cesarean delivery for twins: a systematic review and meta-analysis. Am J Obstet Gynecol. 2003;88:220-227.

14. Sunday-Adeoye I, Twomey ED, Egwuatu VE. Births at Mater Misericordiae Hospital, Afikpo, South Eastern Nigeria. Niger J Clin Pract. 2008;11:231-234.
15. Nwobodo EI, Bobzom DN, Obed J. Twin births at University of Maiduguri Teaching Hospital: incidence, pregnancy complications and outcome. Niger J Med. 2002;11:67-69.

16. Odunsi K, Obinmwanne FC, Jekel J, Otoide VO, Wyshak G, Okonofua FE. White Yam (Dioscorea rotundata) and socioeconomic status as risk factors for twin births in Southwest Nigeria. Presented at the the Fifth International Congress of the Society of Gynecology and Obstetrics of Nigeria, Benin City, Edo State, Nigeria, November 23-28, 1998.

17. Marinho AO, Ilesanmi AO, Ladele OA. A fall in the rate of multiple births in Ibadan and Igbo-Ora, Nigeria. Acta Genet Med Gemellol (Roma). 1986;35:201-204.

18. Kouam L, Kamdom-Moyo J, Doh AS, Ngassa P. Outcome of twin deliveries at the University Teaching Hospital, Yaounde, Cameroon - a 15 year experience. J Obstet Gyneacol. 1998;18:340-344.

19. Igberase GO, Ebeigbe PN, Bock-Oruma A. Twinning rate in a rural mission tertiary hospital in the Niger Delta, Nigeria. J Obstet Gynaecol. 2008;28:586-589.

20. Naymi RS, Rehan N. Prevalence and determinants of caesarean section in a teaching hospital of Pakistan. J Obstet Gynaecol. 2000;20: 479-483.

21. Beazley JM. Caesarean section. In: Chamberlain G, Turnbull SA, editors. Obstetrics, 1st ed. Churchill Livingstone; 1993.

22. Ward RH, Whittle M, editors. Multiple Pregnancy. London, UK: Royal College of Obstetricians and Gynaecologists Press; 1995.

23. Barrett JF, Ritchie WK. Twin delivery. Best Pract Res Clin Obstet Gynaecol. 2002;6:43-56.
International Journal of Women's Health

\section{Publish your work in this journal}

The International Journal of Women's Health is an international, peerreviewed open-access journal publishing original research, reports, reviews and commentaries on all aspects of women's healthcare including gynecology, obstetrics, and breast cancer. Subject areas include: Chronic conditions (migraine headaches, arthritis, osteoporosis);

\section{Dovepress}

Endocrine and autoimmune syndromes; Sexual and reproductive health; Psychological and psychosocial conditions. The manuscript management system is completely online and includes a very quick and fair peer-review system. Visit http://www.dovepress.com/ testimonials.php to read real quotes from published authors. 